\title{
Employee Voice and its Relation to the Morale of Employees in the IT Sector in South India
}

\author{
Shahab Muhammed* and Devi Soumyaja ${ }^{\dagger}$
}

\begin{abstract}
The study was undertaken to understand the influence of employee voice (the degree of an employee's say and influence in workplace decisions) on employee morale (job satisfaction, outlook, and feelings of well- being) in the IT sector. A survey was carried out among a sample of 90 IT employees with less than ten years of experience. A standardised questionnaire was used to carry out the survey. The study results indicate that employee voice has a positive influence on employee morale. Statistical analysis also indicates that there is a gender difference with respect to employee voice. The study aims to encourage management to promote a culture of increased opportunities for employee voice in a way that would, in turn, help in improving employee morale.
\end{abstract}

Keywords: Employee Voice, Employee Morale in IT Employees, Gender in Workplace

\section{Introduction}

The extent to which employees communicate upward with suggestions, ideas, and information about problems or issues of concern can have tremendous implications for an organisation's performance and even its survival. To respond appropriately to dynamic business conditions, make good decisions, and correct

* Power BI, Limner Consulting, Kozhikode, Kerala; shahab114@gmail.com † Cochin Institute of Science and Technology, Cochin University, Kerala, India; devisoumyaja@gmail.com 
problems before they escalate, top managers need information from employees at the lower levels in the organisation-information that may not otherwise come to their awareness (Milliken, Morrison \& Hewlin, 2003). Employee voice exists where everyone in the organisation feels that they have a say and that their voice is heard and listened to, and their views are taken into account when decisions are being discussed. Employee voice may affect the morale of the employee and thus his or her performance. Employee morale is defined as job satisfaction, outlook, and feelings of wellbeing an employee has within a workplace setting.

Within organisations, employees continually confront situations where they are faced with the decision of whether to speak up (i.e., voice) or remain silent when they have potentially useful information or ideas. In recent years, there has been a rapidly growing body of conceptual and empirical research, in foreign countries, focussed on a better understanding of the motives underlying voice; individual and situational factors that increase employee voice behaviour; and the implications of voice and silence for employees, work groups, and organisations. Yet this literature has notable gaps and unresolved issues, and it is not entirely clear where future scholarship should be directed. But when it comes to India, the case is even worse. The concept of employee voice and its implications in the Indian companies is a major area of research which is yet to be explored, barring some related studies.

In today's corporate world, the big organisations have already realised the value of human assets and have initiated humancentric management approaches. Various changes have been brought in HR practices to keep the employees engaged and motivated throughout. The basic idea is to value the employees and make them feel valued. One of the most important factors which make one feel valued is the acknowledgement of one's opinion. As human beings, everyone has the urge and right to voice their opinion in every social setup and thus, it is no different in any business organisation. Even when it comes to India, the giants in the country have come up with various employee-friendly programs and policies to retain, motivate and, most importantly, value them. However, this may not be true in all sectors in India. 
When we talk about the major sectors that contribute majorly to the economy of the nation, one which comes easily to our mind is the youthful and shining IT sector.

India has become a lucrative place for information technology companies to spread their business due to the advantage of a skilled and low-cost workforce. Many Indian companies are also trying to expand globally, thus making this field more attractive for new recruits. The companies are focusing on quality service and long term association with the clients. Most of the established IT companies in India are very successful at a global level and the startups have also achieved great success despite a large number of IT-based startups.

From the Human Resource point of view, an interesting thing about the IT sector is that despite the immense success it showcases, there is a high level of attrition and employee turnover in the whole industry, according to various research studies. It is one sector where employers find a highly dynamic workforce. Most people choose entry-level jobs in the IT sector (especially BPO profile) simply to land into a safety zone before they find the profession of their choice. Also, the concept of floundering, introduced by Edger Schein, might have impacted this negative trend. This tendency highly affects employers and also the work culture in the IT sector. All these facts make it exciting to study an IT employee's freedom to express the self in his/her working environment.

The aim of this research, therefore, is to probe into the degree of employee voice that exists in Indian IT companies and its relation to the morale of its employees and also to provide some direction for the future scholarship by highlighting important questions that still need to be answered.

\section{Review of Literature}

Employee voice has been an area of research for a while now. With most of the big organisations realising the value of the human asset with them, employers are keen on showing the employees how valuable they are. Though the employees in the IT sector constitute 
a dynamic population, research shows that the IT sector in India is a predominant player in the economic state of the country.

Employee voice covers all types of opportunities where employees can have their say and exert some influence over workplace decisions (Boxall \& Purcell, 2011). Employee voice is also defined as speaking up on important issues and problems in an organisation by employees (Dyne et al., 2003).

The term employee voice elicits different understanding to scholars and practitioners of human resource management. Some of the existing definitions that have been provided for voice are inconclusive as they reflect its application in organisations. Dundon et al. (2004) observed that employee voice, as a concept, has competing meanings. Dundon et al. (2004) have given different definitions of employee voice; first, the expression of individual dissatisfaction raised with line managers or through grievance procedure; secondly, as the expression of collective dissatisfaction raised by trade unions through collective bargaining or industrial action; thirdly, contribution to management decision-making process through upward communication, problem solving, suggestion schemes and attitude surveys; and lastly, through mutual partnership agreements, joint consultative committees and work councils (Anyango, Ojera \& Ochieng, 2015).

A central issue related to voice is the question of why employees do or do not speak up when they have organisationally relevant information, ideas, or concerns. As noted, a key assumption within the voice literature is that the behaviour is intended to be constructive and prosocial (Van Dyne et al., 2003). In other words, it is presumed that the driving motive for voice is the desire to help the organisation or work unit perform more effectively or to make a positive difference for the collective (Ashford et al., 2009; Grant, \& Ashford, 2008). With that said, it should not be assumed that employees who fail to voice, lack such a motive. In fact, just the opposite is often the case. When employees choose to remain silent, the motive to bring about improvement exists, but it is overpowered by other motives (Milliken et al., 2003). That is, despite having potentially important information (a suggestion, information about a problem, a divergent opinion, etc.), and even though the employee is motivated to behave prosocially, other 
motives or considerations cause that employee to withhold the information rather than share it (Morrison \& Milliken, 2000; Pinder \& Harlos, 2001; Van Dyne et al., 2003).

Employee voice is a way of making employees an integral part of the organisation and it has a direct bearing on their performance. This is confirmed by Royer, Waterhouse, Brown and Festing (2008). Providing a voice to these employees provides a rationale for further emotional and human capital investment, with the same kind of returns as noted by Wilkinson et al. (2014). Furthermore, there is a perceived linkage between employee voice and job satisfaction. Employee voice is a form of interaction and can be viewed as a process of organisational justice theory. Organisational justice theory relates to the perceived fairness of processes, outcomes, and interactions within the decision-making processes of an organisation between management and employees (Korsgaard et al., 1995). It is therefore important that the extent and degree of the voice of workers within an organisation should be known as this is believed to have an effect on their performance.

The important reason why this research focusses on the IT sector in India is not only the tremendous importance of the industry and its players in the country but also the level of employee attrition that the IT companies are facing. That phenomenon is explained on the basis of some of the existing literature as quoted below. As with any other professional, what really matters to software professionals is selecting 'the best company to work with', which is what every company is striving to be. The global nature of this industry and 'project-environment' has added new cultural dimensions to these firms. In a value-driven culture, values are determined and shared throughout the organisation. Typically, areas in which values are expressed are performance, competence, competitiveness, innovation, teamwork, quality, customer service, and care and consideration for people. Flat structure, open and informal culture, authority based on expertise and ability rather than position, and flexible-timings are some of the norms software firms follow. The idea is to make the workplace a 'fun place' with the hope of increasing loyalty and commitment (Patil et al., 2011).

Employee morale describes the overall outlook, attitude, satisfaction, and confidence that employees feel at work. When 
employees are positive about their work environment and believe that they can meet their most important career and vocational needs at work, employee morale is positive or high (Heathfield, 2017). Employee morale is the result of various personal and organisational factors. It is determined by the individual's perception of various facets associated with one's job and the workplace. As mentioned earlier, job satisfaction is a sub-set of employee morale and is considered as its vital indicator, and therefore, has also been included in this review. Quite a few studies have been noted wherein employee morale has been studied individually or along with other factors. Masin (2010) added that the benefit of high morale is seen in the form of improved communication, low attrition, high retention, and innovative organisation. Morale also creates a positive working environment and increases productivity per employee ratio.

\section{Methodology}

The objectives of the study are the following:

1. To assess the influence of employee voice on employee morale

2. To assess if the gender of an employee influences his/her voice in the organisation

The sample included 90 employees in the IT sector working across South India with less than 10 years of experience. The sample was collected from various cities like Kochi, Trivandrum, Calicut, Coimbatore, Trichy, Hyderabad, Bengaluru, Mangalore, etc. Convenient sampling was used and the respondents were surveyed using standardised questionnaires. All the items were measured on a five-point Likert scale. Employee voice was measured using 6 item questionnaire developed by Van Dyne (1998) and employee morale was measured using "The assessment of work environment schedule (AWES)" developed by Nolan (1998). All the questionnaires had high reliability. 


\section{Analysis and Results}

The sample consisted of 90 respondents; 52 males, and 38 females. Here, Employee Voice is the independent variable and Employee Morale is the dependent variable. To check the influence of employee Voice on employee Morale, regression technique was carried out using SPSS 21 . The data was found to satisfy all the assumptions of regression analysis.

The R-Square value here was found to be 0.310 . That means $31 \%$ of the changes in employee morale is clearly explained or can be predicted by the employee voice. The overall model was also found to be significant $(\mathrm{F}=5.28,000)$. The coefficient table gives additional information. This helps in formulating the regression line. The constant $B$ value of 1.644 is the intercept. That means if the average value of employee voice is 0 , then the value of employee morale is 1.644. The value 0.606 is the gradient of the regression line.

The mathematical equation of a regression line is ' $y=a x+b$ ' where, $y$ is the unknown value of the dependent variable, $x$ is the known value of the independent or predictor variable, $b$ is the constant or the intercept and $a$ is the slope of the line.

In this case, $b=1.644$ and $a=0.606$.

In this case, Employee Morale $=0.606 *($ Employee Voice $)+1.644$

It is also noted that the significance value is shown at 0.000 which means this is also statistically significant. Thus employee voice has a significant influence on employee morale.

ANOVA was carried out to check the influence of gender on employee voice. From the table, we can see the significance level is 0.000 which is much lower than 0.05 . That means the gender of the employees does influence the voice of the employees in the organisations.

Table 1: ANOVA for checking the influence of Gender on Employee Voice

\begin{tabular}{|c|c|}
\hline F & Sig \\
\hline $\mathbf{1 7 . 5 2 6}$ & 0.000 \\
\hline
\end{tabular}


Table 2: Mean values for Employee Voice

\begin{tabular}{lcc}
\hline \multicolumn{1}{c}{ Gender } & $\mathrm{N}$ & Mean \\
\hline Male & 52 & 3.72 \\
Female & 38 & 3.24 \\
\hline
\end{tabular}

From Table 2, we can identify the difference between the mean value of Employee Voice between Group 1 (Male) and Group 2 (Female). The male group has a significantly higher mean value (3.72) than the female group (3.24) while the standard deviation remains almost the same. So it can be concluded that the male group has a greater voice in organisations than the female group.

\section{Conclusion}

The study focused on measuring the level of employee voice in the IT sector in South India and also its influence on the morale of the employees. The data was collected from various parts of South India. The findings have been able to establish a positive relationship between the employee voice and their morale. This, in turn, justifies the assumption and our alternative hypothesis is accepted. The average employee voice value prevalent in the IT industry, according to this study, is not very good, especially while taking into account the low average age and success of the IT industry in India in general. The industry should give more importance to the voice of the employees.

Another highlight of the study is that it clearly states that the gender of the employee makes a difference in the voicing level of the employee. There can be a number of possible reasons for this. The cultural background of the respondents itself is a big factor. The patriarchal nature of Indian society is also reflected in the study. However, there is scope for conducting a study focusing exclusively on this particular issue. Taking into account the fact that larger organisations, according to this study, shows slightly higher employee voice and even higher employee morale, we can say that smaller companies also should start giving their employees more voice in the working environment with the intention of 
increasing their morale and productivity. The concept of employee voice is a highly discussed and studied topic in foreign countries, especially in Western countries. However, this has not been a major topic of research in India. So there is still a lot of potential for research with respect to employee voice in industries in India.

\section{References}

Abdel-Halim, A. A. (1982). Social support and managerial affective responses to job stress. Journal of Organizational Behavior, 3(4), 281-295.

Anyango, C., Ojera, P., Ochieng, I. (2015). Meaning and application of employee voice. International Journal of Scientific Research and Innovative Technology, 2(5), 10-16.

Ashford, S. J., Sutcliffe, K. M., Christianson, M. K. (2009). Speaking up and speaking out: The leadership dynamics of voice in organizations. In Voice and silence in organizations, 175-202.

Bhatnagar, J. (2007). Talent management strategy of employee engagement in Indian ITES employees: key to retention. Employee Relations, 29(6), 640-663, https://doi.org/10.1108/01425450710826122

Boxall, P., \& Purcell, J. (2011). Strategy and human resource management. Macmillan International Higher Education.

Dundon, T., Wilkinson, A., Marchington, M., \& Ackers, P. (2004). The meanings and purpose of employee voice. The International Journal of Human Resource Management, 15(6), 1149-1170.

Grant, A. M., \& Ashford, S. J. (2008). The dynamics of proactivity at work. Research in Organisational Behavior, 28, 3-34.

Heathfield, S. M. (2016, October 31). Simple ideas for improving employee morale in your workplace. Retrieved from https:// www.thebalance.com/you-can-boost-employee-morale-1918107.

Kothari, C. R. (2000). Research methodology: methods Etechniques. Wishwa Prakshan,

New Delhi.

Korsgaard, M. A., Schweiger, D. M., \& Sapienza, H. J. (1995). Building commitment, attachment, and trust in strategic decision-making teams: The role of procedural justice. Academy of Management Journal, 38(1), 60-84.

Mazin, R. (2010). The effects of high morale on employee performance. Available: http:/ /www.ehow.com [2010, May, 20].

Milliken, F. J., Morrison, E. W., \&amp; Hewlin, P. F. (2003). An exploratory study of employee silence: Issues that employees don't communicate upward and why. Journal of Management Studies, 40(6), 1453-1476. 
Morrison, E. W. (2011). Employee voice behavior: Integration and directions for future research. Academy of Management Annals, 5(1), 373-412.

Pinder, C. C., Harlos, K. P. (2001). Employee silence: Quiescence and acquiescence as responses to perceived injustice. In Research in personnel and human resources management (pp. 331-369). Emerald Group Publishing Limited.

Perlow, L., \& Williams, S. (2003). Is silence killing your company? Harvard Business Review, 81(5), 52-58.

Prasad, K. (2005). Strategic human resource management: text and case. Macmillan India Ltd.: New Delhi.

Patil, R. S., Patil, V., \& Waje, P. (2011). Human resource challenges $\mathcal{E}$ practices in IT industry. Proceedings of the 5th National Conference.

Royer, S., Waterhouse, J., Brown, K., \& Festing, M. (2008). Employee voice and strategic competitive advantage in international modern public corporations-an economic perspective. European Management Journal, 26(4), 234-246.

Van Dyne, L., \& LePine, J. A. (1998). Helping and voice extra-role behaviors: Evidence of construct and predictive validity. Academy of Management Journal, 41(1), 108-119.

Wilkinson, A., Dundon, T., Donaghey, J., \&amp; Freeman, R. (2014). Employee voice: Charting new terrain. In The handbook of research on employee voice: Participation and involvement in the workplace, pp. 1-16. 